\title{
EFFECT OF THERMAL TREATMENT VARIABLES ON THE THERMOGRAVIMETRIC PROPERTIES OF EUCALYPT WOOD
}

\author{
Déborah Nava Soratto ${ }^{l, \star}$, Carlos Miguel Simões da Silva ${ }^{2}$, Benedito Rocha Vital ${ }^{2}$, Angélica de Cássia \\ Oliveira Carneiro ${ }^{2}$, Juliana Jerásio Bianche ${ }^{2}$, Walter Torezani Neto Boschetti ${ }^{2}$, Thaís Pereira Freitas ${ }^{2}$, \\ Juliana Ceccato Ferreira ${ }^{3}$
}

\begin{abstract}
Thermal treatments have the effect of reducing the hygroscopicity and improving the resistance to microbiological attack of wood by the degradation of its chemical constituents. During the treatments, the mass of the wood is reduced, a factor that can affect the quality of the materials according to their use. The objective was to verify the effect of the thermal treatment variables on the thermogravimetric properties and the chemical composition of Eucalyptus grandis. The treatments were carried out in a vacuum oven with three atmosphere conditions - vacuum; $\mathrm{N}_{2}$; vacuum $+\mathrm{N}_{2}$ at temperatures of 140,180 and $220{ }^{\circ} \mathrm{C}$ for 6 hours. It was observed that the mass loss during treatments differed only according to the temperatures used. The extractive content, total lignin and holocellulose presented significant changes only at $220^{\circ} \mathrm{C}$ in all three atmospheres. In the thermogravimetric analysis, the greatest value of residual mass was found in the treatment that used nitrogen and $220^{\circ} \mathrm{C}$, thus demonstrating that this treatment was more invasive, leading to the conclusion that the vacuum application can help to reduce the degradation of the constituents of the eucalypt wood. Wood, which can lead to the production of thermally treated wood without great losses in the mechanical properties.
\end{abstract}

Keywords: Eucalyptus grandis, chemical composition, mass loss, thermally treated wood thermogravimetric analysis.

\section{INTRODUCTION}

According to Xing and Li (2010), wood, for some applications, may require greater biological durability and better dimensional stability and, according to Inari et al. (2007), thermorectification or heat treatment is a way of modifying the chemical characteristics of the wood. For instance, Ayata et al. (2017) cited significant improves on the resistance to fungi decay for both softwood and hardwood species. Furthermore, Yildiz et al. (2006) add that the heat treatment can modify the aesthetic appearance, hygroscopicity, and weather resistance, in addition to improving dimensional stability and durability. This mode of treatment of wood can be done in a number of ways, varying the temperatures used, the time the material remains exposed to temperature, the atmosphere of the treatment site and the catalyst used. Also, there is the influence of the specific characteristics of the treated wood species.

During the application of the treatments, the mass of the treated parts reduces, and the authors Welzbacher et al. (2007) reported that this decrease due to the heat treatment could be a reliable and accurate parameter to predict the resistance to decomposition of the thermally treated wood.

Esteves and Pereira (2009) subjected wood samples to heat treatment in an inert atmosphere, with temperatures between 200 and $230^{\circ} \mathrm{C}$, and verified a reduction of the hydrophilic characteristic of the wood due to the modification of the carbohydrates and lignin present in it. Likewise, Martinka et al. (2014) report that using thermal treatment of spruce wood increases the lignin content, reduces the proportion of hemicelluloses,

\footnotetext{
${ }^{1}$ Universidade Federal de Mato Grosso do Sul (UFMS), Campus CPCS, Chapadão do Sul, MS, Brazil.

${ }^{2}$ Universidade Federal de Viçosa (UFV), Departamento de Engenharia Florestal, Viçosa, MG

, Brazil.

${ }^{3}$ Universidade Federal de Jataí (UFJ), Jataí, GO, Brazil.

•Corresponding author: deborahsoratto@gmail.com

Received: 24.08.2018 Accepted: 07.02.2020
} 
and also slightly reduces the degree of average polymerization of the cellulose. These authors further describe that these modifications occur when increasing the maximum temperature and the treatment time.

At temperatures below $150^{\circ} \mathrm{C}$, the volatilization of some extractives and the loss of free water while above this temperature break the chemical bonds of more stable products, leading to the formation of acetic acid, formic acid, methanol, $\mathrm{CO}$ and $\mathrm{CO}_{2}$ (Bourgois and Guyonnet 1988). Dehydration of the wood also occurs through the loss of constituent water, detected by the decrease in the concentration of OH-groups present in the wood. According to Fengel and Wegener (1989), the heating of cellulose at high temperatures and in air atmosphere leads to the production of carbonyl groups and hydroxyl groups due to the presence of oxygen. However, hemicelluloses are more susceptible to chemical reactions of degradation and less tolerant of the action of heat due to the presence of hydroxyl groupings and their amorphous condition Watanabe et al. (1989).

Other studies may show that some treatment variables affect the final product more than others, as found by Zanuncio et al. (2014), who verified that the temperature used was more effective in altering the chemical composition of the wood than the duration of the treatments. Moura et al. (2012), for example, by investigating wood of two different species, Eucalyptus grandis and Pinus caribaea var. hondurensis, found that the increase in the maximum treatment temperature resulted in higher mass losses, and they also mentioned that the losses were higher in the former than in the wood of the latter species. Thus, also relevant is the chemical composition of each species of wood, especially between hardwoods and softwoods. The composition of the hardwood hemicelluloses has an influence on the greater loss of mass. Softwoods contain mainly arabinoglucoronoxylan and galactoglucomannan, while hardwoods contain a lower amount of glucomannan and mainly glucoxylan, which are strongly acetylated, compared to softwood hemicelluloses (Fengel and Wegener 1989, Sjöström 1981). In addition, acetic acid released during the deacetylation of hemicellulose catalyzes the depolymerization of less ordered carbohydrates such as hemicelluloses and amorphous cellulose (Prins et al. 2006).

The atmosphere conditions used for the thermal treatment, such as vacuum, nitrogen, steam or other one that limit the $\mathrm{O}$, concentration, can influence directly on its efficiency and final quality (Wentzel et al. 2019). Araújo et al. (2012), comparing wood treated in the press and in the vacuum oven, concluded that the thermal treatment in the press can produce undesirable effects on the mechanical properties, while the material treated in the vacuum oven with a controlled atmosphere obtained lower losses in the same properties. In the same way, Araújo et al. (2016) also verified that heat treatment in a vacuum resulted in a modified wood that was less hygroscopic and significantly different when compared to wood treated under a nitrogen atmosphere.

Candelier et al. (2013) used vacuum and nitrogen atmospheres with a temperature of $220^{\circ} \mathrm{C}$ in both, and concluded that the effect of the vacuum allows the removal of products from the degradation of the volatiles produced by the wood. This removal has the consequence of limiting the acid degradation of polysaccharides, a phenomenon occurring in the treatment with nitrogen, for example, due to the formation of acetic acid and the recondensation of products of degradation of the volatiles inside the structure of the wood as a result of the non-activation of the vacuum.

In this way, knowing that the heat treatment and its variables are the cause of the chemical degradation of wood and consequently generate a loss of mass in the treated material, it is possible to say that control of the mass loss can be a way to control the quality of the wood. Therefore, this study is based on the investigation of the effects of heat treatment variables, temperature and treatment atmosphere on the loss of mass of the treated wood of Eucalyptus sp., seeking to answer which temperature and atmosphere should be used according to the purpose of the wood.

\section{MATERIAL AND METHODS}

\section{Heat treatment}

Eucalyptus grandis boards were obtained from a sawmill located in the municipality of Viçosa/MG, Brazil. The planks were conditioned in a dry, airy, covered environment, arranged in stacked cells, until they reached a moisture content close to $12 \%$ (dry basis). The initial dry weight was calculated based on the $12 \%$ initial moisture content. Subsequently, the material was sectioned in pieces with mean dimensions of $60 \times 7,5$ $\mathrm{x} 2 \mathrm{~cm}$ (length, width and thickness) and subjected to selection, discarding visibly non-standard parts or defects such as knots and cracks. The samples were then identified and their mass values checked for subsequent 
calculations of the mass loss of the respective treatments to which they were subjected.

The heat treatment of wood was carried out in a Marconi vacuum oven model MA-027 (São Paulo, Brazil), equipped with temperature, pressure, and vacuum control, and gas application. Treatments were applied in three atmosphere conditions - vacuum; nitrogen $\left(\mathrm{N}_{2}\right)$; vacuum + nitrogen $\left(\mathrm{N}_{2}\right)$. For the first two conditions, the material was placed in a vacuum oven already heated to the desired temperature, which was then applied for 6 hours. For the third condition, the samples were subjected to three levels: one hour at room temperature in the vacuum; one hour at $140^{\circ} \mathrm{C}$ in nitrogen, and four hours at the desired final temperature in the same atmosphere as above.

\section{Properties evaluated}

In addition to the values of mass loss, the structural chemical composition - contents of extractives, total lignins and holocelluloses - and the thermogravimetric properties of the samples submitted to each of the treatments were evaluated.

The extractive contents were determined according to the TAPPI 204 om-88 standard (TAPPI 2002). The total lignins contents were estimated according to the methodology followed by Pereira et al. (2013). Holocelluloses contents were determined by difference, subtracting from 100 the contents of extractives and total lignins.

The thermogravimetric properties were determined in a Shimadzu DTG-60H apparatus in an atmosphere of nitrogen gas at a constant flow rate of $50 \mathrm{ml} / \mathrm{min}$. The samples were ground and selected between 200 and 270 mesh overlapping sieves and were subjected to controlled heating at an average rate of $10^{\circ} \mathrm{C} \cdot \mathrm{min}^{-1}$ to the maximum temperature of $600{ }^{\circ} \mathrm{C}$.

\section{Experimental design}

The experiment was conducted in a completely randomized design (DIC), in a factorial arrangement, consisting of three atmospheric conditions - vacuum; nitrogen; vacuum + nitrogen - and three final temperatures $-140,180$ and $220^{\circ} \mathrm{C}$, in three replicates, each having six sample units. The data were submitted to Analysis of Variance (ANOVA) and when significant differences were observed at $5 \%$ of significance, the means were compared between treatments by the Tukey test and with respect to the control by the Dunnett test.

\section{RESULTS AND DISCUSSION}

\section{Loss of mass during treatments}

Table 1 shows the values of mass loss during the heat treatment of eucalypt wood. It is observed that the increase in the treatment temperature promoted a greater loss of mass, while the change in the treatment atmosphere did not result in significant changes in these values.

Table 1: Mass loss, in average percentage, occurring during the treatment of Eucalyptus grandis. wood as a function of the treatment temperature and atmosphere.

\begin{tabular}{|c|c|c|}
\hline Effect & Condition & Mass loss (\%) \\
\hline \multirow{3}{*}{ Temperature of treatment } & $140^{\circ} \mathrm{C}$ & $6,71 \mathrm{c}$ \\
\cline { 2 - 3 } & $180^{\circ} \mathrm{C}$ & $11,16 \mathrm{~b}$ \\
\cline { 2 - 3 } & $220^{\circ} \mathrm{C}$ & $17,34 \mathrm{a}$ \\
\hline \multirow{3}{*}{ Atmosphere of treatment } & Nitrogen & $12,55 \mathrm{a}$ \\
\cline { 2 - 3 } & Vacuum & $11,32 \mathrm{a}$ \\
\cline { 2 - 3 } & Vacuum + nitrogen & $11,33 \mathrm{a}$ \\
\hline
\end{tabular}

Means followed by the same lowercase letters, for each effect along each column, did not differ significantly from each other by the Tukey test at $5 \%$ probability. 
The mass losses of all the treatments applied are in accordance with the values indicated by the "Thermowood" process for heat treatment of wood. According to Esteves et al. (2008), this Finnish patent recommends a minimum mass loss of 3\% in order to increase dimensional stability and at least $5 \%$ to increase the natural durability of the wood. However, some values found in the present study are significantly higher than those found by other studies, such as Brito et al. (2006), who treated wood of Eucalyptus grandis and Olarescu et al. (2013), who treated lime wood. These authors verified mass losses of up to, respectively $9,7 \%$ and $9,3 \%$ for woods subjected to thermal treatments at $200{ }^{\circ} \mathrm{C}$.

Araújo et al. (2016) heat-treated wood of different species native to Brazil - Aspidosperma populifolium, Dipteryx odorata and Mimosa scabrella - using treatment, temperature and atmosphere conditions similar to those of the present study. However, by using a treatment time of only one hour, the authors found mass loss values of at most $2,21 \%$ for treatment at $220{ }^{\circ} \mathrm{C}$. In addition, mean values in the vacuum condition, relative to the nitrogen atmosphere, were significantly higher for some species. Compared with the present study, performed for a longer treatment time (6 hours), it can be observed that, in addition to the temperature, the heating time has great relevance in the thermal degradation of the wood.

\section{Chemical composition}

Table 2 shows the structural chemical composition of thermally treated eucalypt wood samples. Changes in the proportions of the components are observed, with increases in extractive and lignin contents and decreases in holocelluloses contents due to the heat treatment in relation to the control samples. However, there was no statistical difference between the treatments, only those with respect to the control.

Table 2: Structural chemical composition of Eucalyptus grandis wood subjected to thermal treatment under different temperature and atmosphere conditions.

\begin{tabular}{|c|c|c|c|c|}
\hline \multicolumn{2}{|c|}{ Treatment } & Holocelluloses (\%) & Lignin $(\%)$ & Extractives $(\%)$ \\
\hline \multicolumn{2}{|c|}{ Untreated } & 67,62 & 28,94 & 3,44 \\
\hline \multirow{3}{*}{ Vacuum } & $140^{\circ} \mathrm{C}$ & 65,22 & 29,78 & 5,00 \\
\hline & $180^{\circ} \mathrm{C}$ & 66,46 & 29,75 & 3,79 \\
\hline & $220^{\circ} \mathrm{C}$ & $61,21^{*}$ & $32,03 *$ & $6,77^{*}$ \\
\hline \multirow{3}{*}{ Nitrogen } & $140^{\circ} \mathrm{C}$ & 66,67 & 29,90 & 3,43 \\
\hline & $180^{\circ} \mathrm{C}$ & 65,60 & 29,58 & 4,82 \\
\hline & $220^{\circ} \mathrm{C}$ & $57,44^{*}$ & $34,81^{*}$ & $7,75^{*}$ \\
\hline \multirow{3}{*}{$\begin{array}{c}\text { Vacuum } \\
+ \\
\text { Nitrogen }\end{array}$} & $140^{\circ} \mathrm{C}$ & 66,22 & 30,01 & 3,77 \\
\hline & $180^{\circ} \mathrm{C}$ & $63,71 *$ & 31,08 & 5,21 \\
\hline & $220^{\circ} \mathrm{C}$ & $58,96^{*}$ & $33,24 *$ & $7,80^{*}$ \\
\hline
\end{tabular}

Means followed by * differ significantly from the control at $5 \%$ significance by the Dunnett test.

The sum of the contents of hemicelluloses and cellulose is denominated holocelluloses and corresponds to the most expressive mass fraction of the wood. The reduction in its contents, mainly in the treatment at 220 ${ }^{\circ} \mathrm{C}$, occurs with the thermal degradation of the wood starting at the temperatures used in this study. The results are in agreement with Zanuncio et al. (2014), who evaluated the heat treatment of Eucalyptus wood at different temperatures up to $230{ }^{\circ} \mathrm{C}$ and times up to 7 hours. The authors observed the reduction of holocelluloses contents from $66,27 \%$ of the control to $54,12 \%$ in the most altered samples. According to Yang et al. (2007) and Bach et al. (2014), in this temperature range, mass loss occurs mainly in the fraction of hemicelluloses due to its structure with a low degree of polymerization, which makes it less stable to heating compared to cellulose, which presents the most compact and polymerized structure.

The lignin content of wood treated at $220^{\circ} \mathrm{C}$ was significantly higher than the control. Similar results were found by Moura et al. (2012), Zanuncio et al. (2014) and Da Silva et al. (2016), who observed increases in the lignins concentration when thermally treating Eucalyptus wood. The lignins contents increased proportionally in the wood because of the degradation of other constituents, especially the hemicelluloses, as discussed by 
Figueiró et al. (2019). Lignins are phenolic macromolecules with high thermal stability (Yang et al. 2007) and with very low mass loss rates during heat treatment, thus explaining the concentration of their contents in thermally treated wood.

In general, the treatments caused an increase, in proportion, in the extractive content. However, this increase was only significant at the temperature of $220{ }^{\circ} \mathrm{C}$, regardless of the method used, when compared to the control. These results corroborate the results already found by Zanuncio et al. (2014) and Da Silva et al. (2016), who observed increases in the extractive content for the heat treatments performed at 230 and 220 ${ }^{\circ} \mathrm{C}$, respectively. The increase in the extractive content can be explained by the formation and modification of other compounds, such as the degradation of the hemicelluloses, for example, forming soluble products in the reagents used for the removal of extractives Esteves et al. (2011), and also by the formation of compounds during the heat treatment, especially at the higher temperatures.

\section{Thermogravimetric analysis}

Figure 1 shows the curves obtained from the thermogravimetric analyses (TGA) and their respective derivatives (DTG) of the thermally treated eucalypt wood under different temperature and atmosphere conditions. The graphs were plotted between the temperatures of 200 and $400{ }^{\circ} \mathrm{C}$, because the thermal degradation was more relevant in this temperature range, and they help to visualize the thermal degradation, allowing us to verify, with the derivatives, the thermal decomposition peaks of the wood, which has already undergone heat treatment previously.

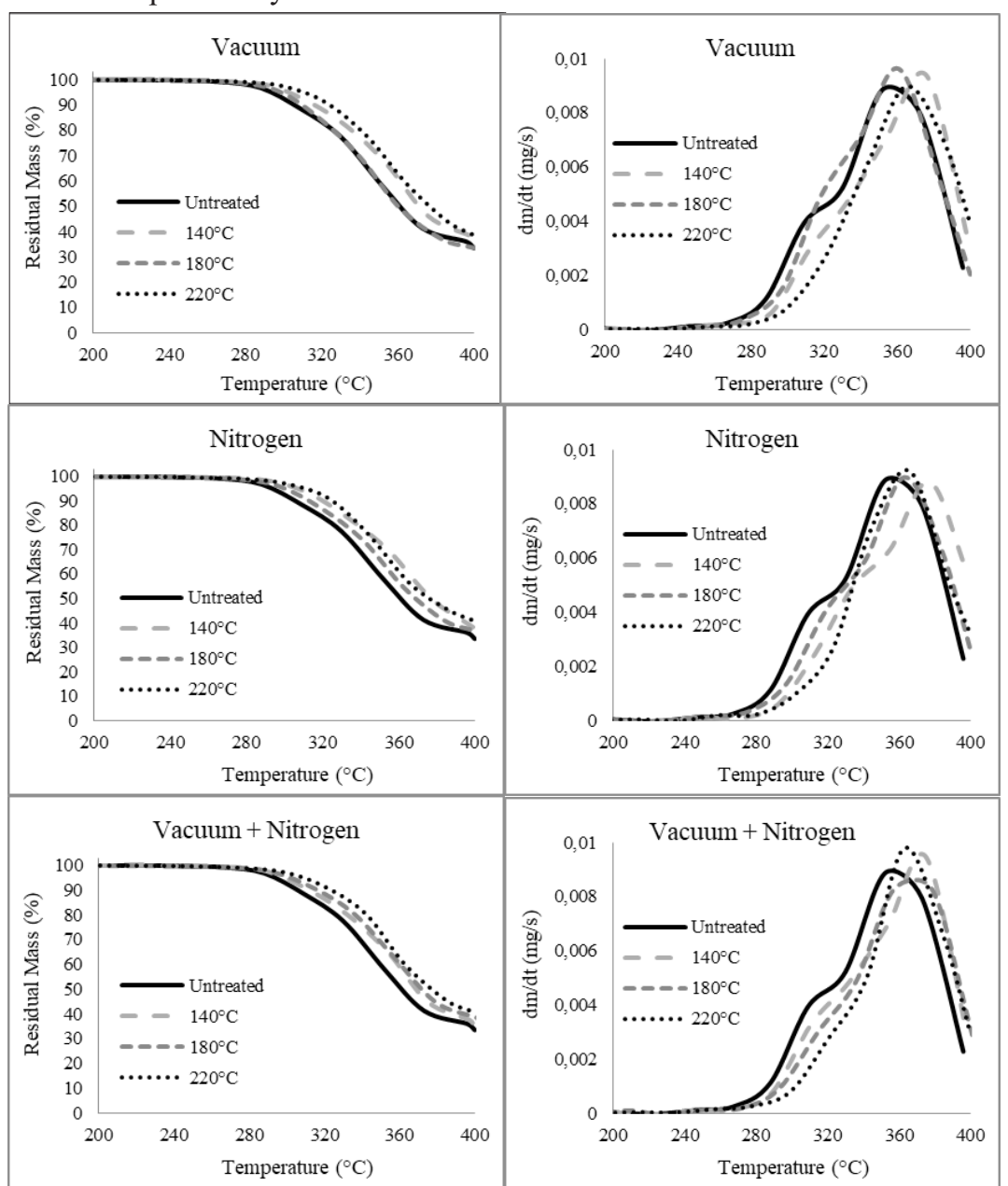

Figure 1: Graphs obtained from the thermogravimetric analysis (TGA) and the respective thermogravimetric derivative (DTG) of thermally treated Eucalyptus grandis woods at different temperatures - 140, 180 and $220^{\circ} \mathrm{C}$ - as a function of the treatment atmosphere condition. 
Figure 1 shows the increase in stability of the thermal degradation of the thermally treated wood in relation to the untreated wood (control). The samples submitted to the treatments at higher temperatures showed a mass loss with late onset and at lower rates, besides the increase of the residual mass in the thermogravimetric analysis. The effect of the treatment atmosphere was less significant in the thermal degradation profiles, and its effect is discussed later in Table 3.

The thermal degradation DTG profile of the control samples is divided into two characteristic mass loss peaks. According to Bach et al. (2014), the first peak, which in the present study was between 280 and $320^{\circ} \mathrm{C}$, is attributed to thermal degradation of hemicelluloses. The hemicelluloses are more reactive and susceptible to heat action due to their amorphous structure, less compacted, with a low degree of polymerization and with high amounts of hydroxyls Yang et al. (2007). The reduction and absence of this peak in the thermally treated samples indicate, therefore, a lower content of these polysaccharides due to the thermal degradation that occurred during the treatment.

The second mass loss peak, which in the present study was between 320 and $400{ }^{\circ} \mathrm{C}$, is attributed to the thermal degradation of cellulose (Shen et al. 2010, Bach et al. 2014). The peak mass loss for the cellulose is higher than the hemicelluloses, due to the greater amount of energy required for the depolymerization of the cellulose chain and the breakdown of its monomers. The increase of this peak in some thermally treated samples suggests a concentration in the cellulose contents as a consequence of the degradation of hemicelluloses, as discussed by Da Silva et al. (2016).

In the DTG graphs it was not possible to observe any mass loss peak that could be related to lignin degradation. Lignins are macromolecules formed by aromatic units that are characterised by high stability and thermal degradation, presenting low rates of mass loss (Yang et al. 2007, Haykiri-Acma et al. 2010). According to Pereira et al. (2013), the final residual mass presented by the TGA graphs consists mainly of residual lignin molecules. The higher percentage values of residual mass above $400{ }^{\circ} \mathrm{C}$ therefore indicate higher lignin contents in the thermally treated samples than in the control sample.

Table 3 shows the mass loss percentage values obtained in each temperature range during the thermogravimetric analysis. The highest variations were observed for the wood samples submitted to the thermal treatment under nitrogen atmosphere. In this condition, samples treated up to $180{ }^{\circ} \mathrm{C}$ showed an increase in mass loss in the temperature range between 200 and $300{ }^{\circ} \mathrm{C}$, followed by a reduction in the range between 300 and $400{ }^{\circ} \mathrm{C}$. For the samples treated at $220^{\circ} \mathrm{C}$, however, the trend showed a significant reversal, with reduction of mass loss between 200 and $300^{\circ} \mathrm{C}$ and increase between 300 and $400{ }^{\circ} \mathrm{C}$.

Table 3: Mass loss (\%), during the thermogravimetric analysis, as a function of the temperature ranges for the heat treatments and the control.

\begin{tabular}{|c|c|c|c|c|c|}
\hline \multirow{2}{*}{\multicolumn{2}{|c|}{ Treatment }} & \multicolumn{4}{|c|}{ Temperature range $\left({ }^{\circ} \mathrm{C}\right)$} \\
\hline & & Up to 200 & 200-300 & $300-400$ & Residual mass \\
\hline \multicolumn{2}{|c|}{ Untreated } & 1,19 & 12,13 & 53,16 & 33,52 \\
\hline \multirow{3}{*}{ Vacuum } & $140^{\circ} \mathrm{C}$ & 0,91 & 12,73 & 52,43 & 33,93 \\
\hline & $180^{\circ} \mathrm{C}$ & 1,33 & 17,53 & 46,37 & 34,77 \\
\hline & $220^{\circ} \mathrm{C}$ & 1,16 & 7,17 & 54,46 & 37,21 \\
\hline \multirow{3}{*}{ Nitrogen } & $140^{\circ} \mathrm{C}$ & 1,04 & 15,60 & 48,08 & 35,28 \\
\hline & $180^{\circ} \mathrm{C}$ & 1,01 & 18,86 & 45,17 & 34,96 \\
\hline & $220^{\circ} \mathrm{C}$ & 1,06 & 5,91 & 54,58 & 38,44 \\
\hline \multirow{3}{*}{$\begin{array}{c}\text { Vacuum } \\
+ \\
\text { Nitrogen }\end{array}$} & $140^{\circ} \mathrm{C}$ & 0,84 & 13,33 & 52,15 & 33,68 \\
\hline & $180^{\circ} \mathrm{C}$ & 1,18 & 15,01 & 47,61 & 36,19 \\
\hline & $220^{\circ} \mathrm{C}$ & 0,96 & 6,21 & 55,06 & 37,76 \\
\hline
\end{tabular}


As discussed by Candelier et al. (2013), thermal treatments performed under vacuum and nitrogen conditions present significant differences. According to these authors, unlike the vacuum that facilitates the removal of the volatile organic compounds generated during the heat treatment, the nitrogen condition does not allow such an efficient elimination of these compounds, allowing them to remain for longer in contact with the wood. Some of these compounds have acidic $\mathrm{pH}$, especially acetic acid, and they act as catalysts to accelerate the chemical modification reactions of polysaccharides, mainly hemicelluloses. With this, the nitrogen atmosphere usually presents greater chemical modifications of the wood compared to vacuum. Although there were no significant differences in our study, similar trends to that one were observed among the mean values.

Temperatures of 140 and $180^{\circ} \mathrm{C}$ are not sufficient to promote significant mass losses during heat treatment. However, they may initiate chemical modifications in the constituents of wood, especially hemicelluloses, due to thermal degradation. Thus, the fraction of hemicelluloses, with their altered chemical structure, tends to be more susceptible to heat exposure, increasing their mass loss between 200 and $300{ }^{\circ} \mathrm{C}$. As a consequence, the mass loss between 300 and $400{ }^{\circ} \mathrm{C}$ tends to decrease. In addition, the milder heat treatments promote an increase in the crystallinity of the cellulose and its thermal stability (Esteves and Pereira 2009), also contributing to the lower mass loss in the mentioned temperature range.

The most intense heat treatment, applied at $220^{\circ} \mathrm{C}$, was sufficient to degrade a significant part of the hemicelluloses, thus concentrating the cellulose and lignin contents in the final solid fraction, as discussed in Table 2 and Figure 1. With this, the wood samples treated at that temperature showed lower mass loss between 200 and $300{ }^{\circ} \mathrm{C}$ during the thermogravimetric analysis. The loss of mass in the temperature range of 300 to $400{ }^{\circ} \mathrm{C}$ and the residual mass above $400^{\circ} \mathrm{C}$ presented higher values in relation to the control, due to the higher concentrations of cellulose and lignin, respectively.

\section{CONCLUSIONS}

According to the results obtained in the present study, for thermally treated Eucalyptus grandis wood up to $220{ }^{\circ} \mathrm{C}$ under vacuum and / or nitrogen atmosphere, it can be concluded that:

The temperature has a direct effect on the heat treatment efficiency of this wood, promoting gradual increases in mass loss, while the treatment atmosphere has a less significant effect.

The thermally treated wood presents significant changes in the proportions of the chemical constituents, mainly due to the increase in temperature, such as lower holocelluloses contents and higher lignin and extractive contents in relation to the control samples.

There was greater thermal stability, with a delay at the beginning of mass loss and an increase in residual mass values during thermogravimetric analysis.

For the eucalypt wood, the nitrogen atmosphere tends to present larger changes in the chemical components when compared to the vacuum atmosphere as a function of the temperature increase.

The results show that the heat treatment is capable of promoting significant changes in the structure and chemical composition of Eucalyptus grandis wood and allows us to observe the best temperature and atmosphere according to the level of chemical decomposition and mass loss. It is interesting to seek methods that treat the wood causing the least damage possible for its use. These changes are reflected in the other indices of material quality, so it is necessary to know the treatment condition capable of promoting the most advantageous increments to the purpose for which each type of treated wood is destined. 


\section{REFERENCES}

Araújo, S.O.; Vital, B.R.; Mendoza, Z.M.S.H.; Vieira, T.A.; Carneiro, A.C.O. 2012. Properties of thermorectificated wood of Eucalyptus grandis and Eucalyptus. Scientia Forestalis 40 (95): 327-336.

Araújo, S.O.; Vital, B.R.; Oliveira, B.; Carneiro, A.C.O.; Lourenço, A.; Pereira, H. 2016. Physical and mechanical properties of heat treated wood from Aspidosperma populifolium, Dipteryx odorata and Mimosa scabrella. Maderas-Cienc Tecnol 18 (1): 143-156. https://doi.org/10.4067/S0718-221X2016005000015.

Ayata, U.; Akcay, C.; Esteves, B. 2017. Determination of decay resistance against Pleurotus ostreatus and Coniophora puteana fungus of heat-treated scotch pine, oak and beech wood species. Maderas-Cienc Tecnol 19(3):309-316. https://doi.org/10.4067/S0718-221X2017005000026.

Bach, Q.; Tran, K.; Skreiberg, O.; Khalil, R.A.; Phan, A.N. 2014. Effects of wet torrefaction on reactivity and kinetics of wood under air combustion conditions. Fuel 137: 375-383. https://doi.org/10.1016/j. fuel.2014.08.011.

Bourgois, J.; Guyonnet, R. 1988. Characterization and analysis of torrified wood. Wood Science Technology 22 (2): 143-155. https://doi.org/10.1007/BF00355850.

Brito, J.O.; Garcia, J.N.; Bortoletto Junior, G.; Pessoa, A.M.C.; Silva, P.H.M. 2006. The density and shrinkage behavior of Eucalyptus grandis wood submitted to different temperatures of thermorectification. Cerne 12 (2): 182-188. http://cerne.ufla.br/site/index.php/CERNE/article/view/413.

Candelier, K.; Dumarçay, S.; Pétrissans, A.; Desharnais, L.; Gérardin, P.; Pétrissans, M. 2013. Comparison of chemical composition and decay durability of heat treated wood cured under different inert atmospheres: nitrogen or vacuum. Polymer Degradation and Stability 98: 677-681. https://doi.org/10.1016/j. polymdegradstab.2012.10.022.

Da Silva, C.M.S.; Carneiro, A.C.O.; Pereira, B.L.C.; Vital, B.R.; Alves, I.C.N.; Magalhães, M.A. 2016. Stability to thermal degradation and chemical composition of woody biomass subjected to the torrefaction process. European Journal of Wood and Wood Products 74 (6): 845-850. https://doi.org/10.1007/s00107-0161060-z.

Esteves, B.M.; Domingos, I.L.; Pereira, H.M. 2008. Pine wood modification by heat treatment in air. BioResources 3 (1): 142-154.

Esteves, B.M.; Pereira, H.M. 2009. Wood modification by heat treatment: a review. BioResources 4 (1): 370-404.

Esteves, B.; Videira, R.; Pereira, H. 2011. Chemistry and ecotoxicity of heat treated pine wood extractives. Wood Science Technology 45 (6): 661-676. https://doi.org/10.1007/s00226-010-0356-0.

Fengel, D.; Wegener, G. 1989. Wood: Chemistry, Ultrastructure, Reactions. Walter de Gruyter, Berlin.

Figueiró, C.G.; Vital, B.R.; Carneiro, A.C.O.; Silva, C.M.S.; Magalhães, M.A.; Fialho, L.F. 2019. Energy valorization of woody biomass by torrefaction treatment: a brazilian experimental study. MaderasCienc Tecnol 21(3): 297-304. https:// doi.org/10.4067/S0718-221X2019005000302.

Haykiri-Acma, H.; Yaman, S.; Kucukbayrak, S. 2010. Comparison of the thermal reactivities of isolated lignin and holocellulose during pyrolysis. Fuel Processing Technology 91: 759-764. https://doi.org/10.1016/J. FUPROC.2010.02.009. 
Inari, G.N.; Petrissans, M.; Gerardin, P. 2007. Chemical reactivity of heat-treated wood. Wood Science Technology 41: 157-168. https://doi.org/10.1007/s00226-006-0092-7.

Martinka, J.; Hroncová, E.; Chrebet, T.; Balog, K. 2014. The influence of spruce wood heat treatment on its thermal stability and burning process. European Journal of Wood and Wood Products 72: 477-486. https://doi.org/10.1007/s00107-014-0805-9.

Moura, L.F.; Brito, J.O.; Silva Júnior, F.G. 2012. Effect of thermal treatment on the chemical characteristics of wood from Eucalyptus grandis W. Hill ex Maiden under different atmospheric conditions. Cerne 18 (3): 449-455. https://doi.org/10.1590/S0104-77602012000300012.

Olarescu, M.C.; Campean, M.; Ispas, M.; Cosereanu, C. 2013. Effect of thermal treatment on some properties of lime wood. European Journal of Wood and Wood Products 72: 559-562. https://doi.org/10.1007/ s00107-014-0809-5.

Pereira, B.L.C.; Carneiro, A.C.O.; Carvalho, A.M.M.L.; Colodette, J.L.; Oliveira, A.C.; Fontes, M.P.F. 2013. Influence of chemical composition of Eucalyptus wood on gravimetric yield and charcoal properties. BioResources 8 (3): 4574-4592.

Prins, M.J.; Ptasinski, K.J.; Jansen, F.J.J.G. 2006. Torrefaction of wood, part 2. Analysis of products. Journal of Analytical Applied Pyrolysis 77: 35-40. https://doi.org/10.1016/j.jaap.2006.01.001.

Shen, D.K.; Gu, S.; Bridgwater, A.V. 2010. The thermal performance of the polysaccharides extracted from hardwood: Cellulose and hemicelluloses. Carbohydrate Polymers 82: 39-45. https://doi.org/10.1016/j. carbpol.2010.04.018.

Sjöström, E. 1981. Wood polysaccharides. In Wood chemistry. Fundamentals and applications. Academic Press 3: 49-67.

TAPPI. 2002. Technical Association of the Pulp and Paper Industry. TAPPI test methods T 204 om-88: solvent extractives of wood and pulp. In: TAPPI Standard Method: Atlanta, GA.

Xing, D.; Li, J. 2010. Effects of heat treatment on thermal decomposition and combustion performance of Larix spp. wood. BioResources 9 (3): 4274-4287.

Yang, H.; Yan, R.; Chen, H.; Lee, D.H.; Zheng, C. 2007. Characteristics of hemicellulose, cellulose and lignin pyrolysis. Fuel 86: 1781-1788. https://doi.org/10.1016/j.fuel.2006.12.013.

Yildiz, S.; Gezer, E.D.; Yildiz, U.C. 2006. Mechanical and chemical behavior of spruce wood modified by heat. Building and Environment 41 (12): 1762-1766. https://doi.org/10.1016/j.buildenv.2005.07.017.

Watanabe, T.; Ohnishi, J.; Yamasaki, Y.; Kaizu, S.; Koshijima, T. 1989. Binding-site analysis of the ether linkages between lignin and hemicelluloses in lignin-carbohydrate complexes by DDQ-oxidation. Agricultural and Biological Chemistry 53: 2233-2252. https://doi.org/10.1080/00021369.1989.10869603.

Welzbacher, C.R.; Brischke, C.; Rapp, A.O. 2007. Influence of treatment temperature and duration on selected biological, mechanical, physical and optical properties of thermally modified timber. Wood Mater Science and Engineering 2: 66-76. https://doi.org/10.1080/17480270701770606.

Wentzel, M.; Brischke, C.; Militz, H. 2019. Dynamic and static mechanical properties of Eucalyptus nitens thermally modified in an open and closed reactor system. Maderas-Cienc Tecnol 21(2):141-152. http:// dx.doi.org/10.4067/S0718-221X2019005000201. 
Zanuncio, A.J.V.; Nobre, J.R.C.; Motta, J.P.; Trugilho, P.F. 2014. Chemistry and colorimetry of thermorectified wood from Eucalyptus grandis W. Mill ex Maiden. Revista Árvore 38 (4): 765-770. 